\title{
Effectiveness of two concentrations 12\% versus $38 \%$ of silver diamine fluoride in arresting cavitated dentin caries among children: a systematic review
}

\author{
Zeinab O. Tolba ${ }^{1,4^{*}}$ D, Heba S. Hamza', Dalia M. Moheb², Hassan E. Hassanein ${ }^{3}$ and Hend M. El Sayed ${ }^{1}$
}

\begin{abstract}
This systematic review was performed to compare the effectiveness of two concentrations (12\% versus 38\%) of silver diamine fluoride (SDF) in arresting cavitated dentin caries among children. A search of randomized clinical trials was performed in six databases: PubMed, Scopus, the Latin American and Caribbean Health Sciences Literature database (LILACS), the Cochrane Library, Turning Research Into Practice (TRIP) database (Trip medical database), and National Institute for Health and Care Excellence (NICE Evidence Search) database. A manual search was performed on the reference lists of all primary studies for additional relevant publications. No restrictions on publication date or languages were involved. Full-text versions of the papers that appeared to meet the inclusion criteria were retrieved for further assessment and data extraction. The initial search identified a total of 373 articles; three publications were found to meet the inclusion criteria. Risk of bias assessment was performed. The three publications agreed that the 38\% SDF had a higher chance of arresting dentin caries in primary teeth than the 12\% SDF concentration. Further trials are needed for establishing a suitable protocol in the view that the higher the SDF concentration and frequency of application, the higher the incidence of black staining.
\end{abstract}

Keywords: Caries, Childhood, Dental fluorosis, Silver diamine fluoride, Systematic review

\section{Background}

Dental caries is a common disease worldwide [1]. The treatment strategies have pursued more radical approach by trying to arrest dental decay via remineralizing therapies rather than the classical restorative treatment. Topical silver diamine fluoride (SDF) application has been introduced with promising effectiveness in arresting active caries and also in preventing new carious lesions [2-4]. It has been especially used in primary teeth because of its manifest potential in special conditions such as early childhood caries (ECC), pediatric patients with special needs, patients suffering from behavioral or medical issues impeding conventional therapy, those with salivary

\footnotetext{
* Correspondence: zeinabomar95@yahoo.com;

zeinab.omar@dentistry.cu.edu.eg

${ }^{1}$ Conservative Dentistry Department, Faculty of Dentistry, Cairo University, 11 EL-Saraya St. Manial, Cairo 11553, Egypt

${ }^{4}$ Giza, Egypt

Full list of author information is available at the end of the article
}

dysfunction, and also those who cannot afford or access regular dental medical care [4].

SDF application is an inexpensive, non-invasive, quick, and painless procedure that has proved to be $89 \%$ more effective than other treatments or placebo. Its use is simple and readily learned by dental health professionals $[4,5]$. SDF acts by promoting remineralization of tooth structure via its fluoride content, whereas its silver component has an anti-bacterial effect [6, 7]. Teeth discoloration is its main disadvantage that might cause dissatisfaction of the patient or his parents [8].

Several protocols have been investigated aiming at optimization of its efficiency to incorporate SDF application in the clinical dental practice [9]. Clinical studies have proved the effectiveness of the $38 \%$ concentration in preventing and arresting ECC [2, 3, 10-12]. However, due to its high fluoride content of 44,800 ppm that poses the risk of dental fluorosis, a low concentration of $12 \%$ has been introduced to minimize such complication [13]. 
The aim of this systematic review is to answer the following participant, intervention, comparator, and outcome (PICO) question: Is the application of $12 \%$ SDF as effective as the $38 \%$ SDF in arresting cavitated dentin caries among children?

\section{Methods}

This systematic review followed the PRISMA statement for reporting systematic reviews and meta-analysis [14].

\section{Information sources and search strategy}

Two independent investigators performed systematic searches for the publications in six databases: PubMed, Scopus, the Latin American and Caribbean Health Sciences Literature database (LILACS), the Cochrane Library, Turning Research Into Practice (TRIP) database (Trip medical database), and National Institute for Health and Care Excellence (NICE Evidence Search) database. The search strategy was based on controlled vocabulary (MeSH terms) of the PubMed database along with free keywords that were combined with the Boolean operator [OR] within each concept of the search strategy. The "participant" and "intervention" concepts from the PICO question were combined with the Boolean operator [AND]. The search was updated till February 1, 2018. The terms used in the PubMed database were as follows: ((("Dental Caries"[Mesh]) OR "Tooth Demineralization”[Mesh])) AND $((()((()(((($ “silver diamine fluoride" [Supplementary Concept]) OR silver diamine fluoride) OR silver diamine fluoride caries) OR (silver diamine fluoride and caries)) OR prevention of secondary caries by silver diamine fluoride) OR caries silver diamine fluoride) OR silver diamine fluoride root) OR silver diamine fluoride clinical) OR silver diamine fluoride pulp) OR silver diamine fluoride root caries) OR silver diamine fluoride in dentistry) OR effectiveness silver diamine fluoride) OR silver diamine fluoride pediatric). The same strategy was used for the other electronic databases.

A manual search was performed on the reference lists of all primary studies for additional relevant publications. No restrictions on publication date or language were applied. Grey literature was explored using the Grey Literature Report. To find unpublished and ongoing trials, the ClinicalTrials.gov registry (www.clinicaltrials.gov) was searched. Full-text versions of the papers that appeared to meet the inclusion criteria were retrieved for further assessment and data extraction.

\section{Eligibility criteria}

Only randomized clinical trials (RCTs) comparing the effectiveness of the $12 \%$ versus $38 \%$ concentrations of SDF in arresting cavitated dentin caries among children aged 3-12 years old were included.

\section{Study selection and data collection process}

The articles were selected by title and abstract according to the described eligibility criteria. Articles appearing in more than one database were considered only once. The non-English studies were translated into English.

\section{Data collection and analysis}

Two independent investigators reviewed the full texts that met the inclusion criteria. Each included study received an ID, combining first author, and year of publication. Data about subjects including age (mean $\pm \mathrm{SD}$ and range/years), type of teeth, total number of patients/ drop-outs, grouping, trial length (months), follow-up period (months), application frequency, and outcome were extracted.

\section{Risk of bias in individual studies}

The risk of bias of each study was performed according to the risk of bias assessment tool recommended by the "Cochrane Handbook for Systematic Review of Interventions" [15]. The Collaboration's recommended tool for assessing the risk of bias is a domain-based evaluation. The assessment criteria contained 6 domains: sequence generation, allocation concealment, blinding, incomplete outcome data, selective reporting, and other possible sources of bias. Critical assessments were made separately for different domains. Judgment for each entry consisted of recording "yes" (low risk of bias), "no" (high risk of bias), or "unclear" (either lack of information or uncertainty over the potential for bias).

\section{Results}

\section{Search results and study selection}

The initial search identified a total of 373 articles. Among them, 194 articles were removed being duplicate records. After screening the title and abstract, two independent investigators reached separately an agreement on three publications that fulfilled the search eligibility criteria and subsequently their full-texts were studied (Fig. 1).

\section{Characteristics of included articles and assessment of the risk of bias}

The characteristics of the three selected publications are shown in Table 1. All were clinical trials [16-18]. The mean (SD) age of the patients was $5.2(1.2)$ years [16] and 3.8 (0.6) years $[17,18]$. The three publications involved only primary teeth. The number of patients studied was 976 children [16] and $888[17,18]$. SDF was used in two concentrations $12 \%$ versus $38 \%$. The protocol of SDF application in the first publication was one application for 2 min at baseline [16]. In the latter two, the study subjects were treated every 6 months: for the annual groups, SDF was applied alternating with normal saline as a placebo, 


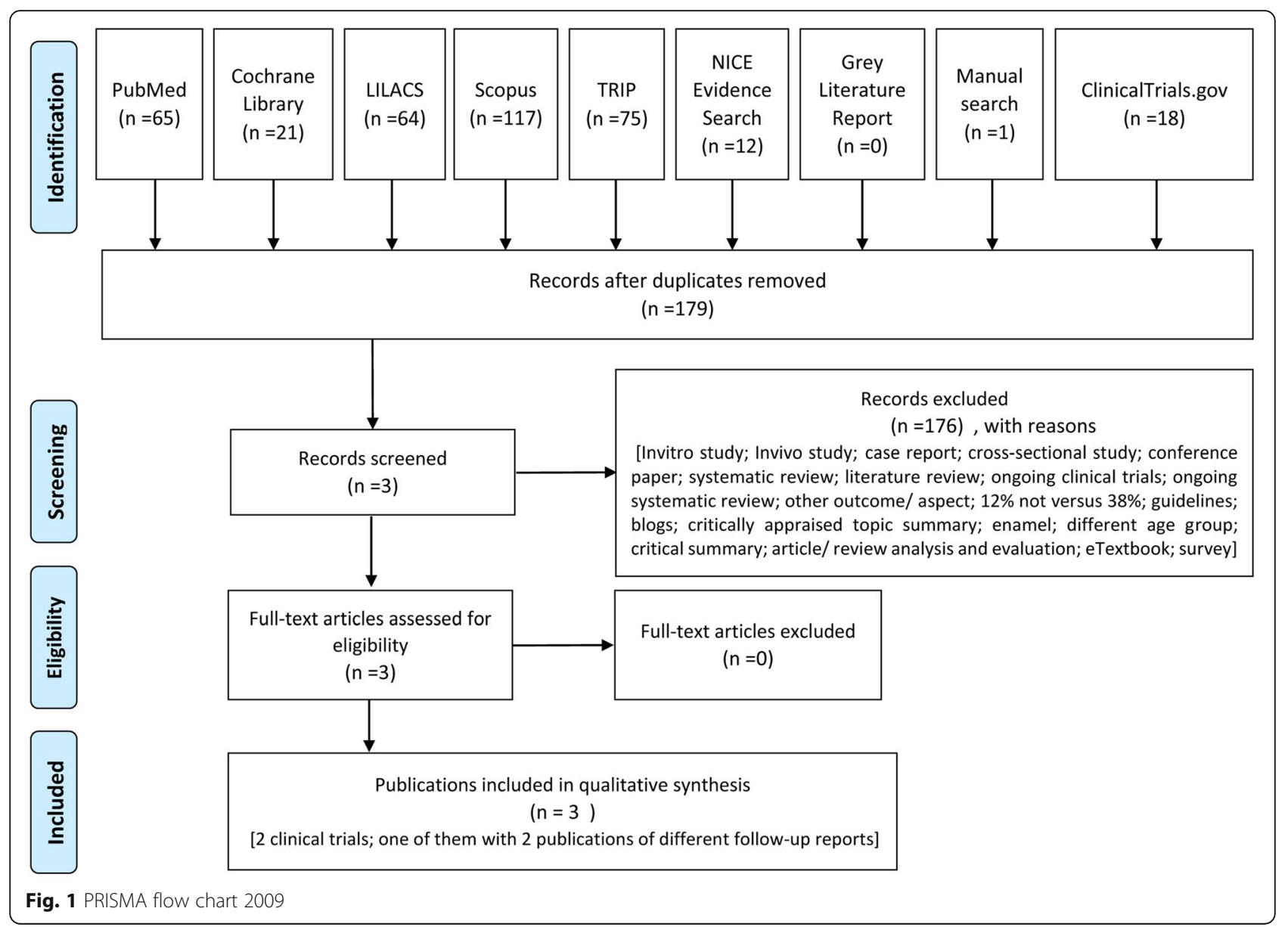

while in the biannual group, SDF was applied in each visit $[17,18]$. The follow-up periods ranged from 6 to 30 months: 6 and 12 months follow-up [16, 17], 18 months follow-up [17], 24 months follow-up [16, 18], and 30 months follow-up [18]. The outcomes were as follows:

\section{Caries arrestment-12\% SDF versus $38 \%$ SDF}

This is summarized in Tables 1 and 2 .

Yee et al. [16] found that at 6,12, and 24 months, the mean number of arrested carious surfaces was significantly higher in the two groups treated with 38\% SDF than in the $12 \% \mathrm{SDF}$ and control groups (Table 1). The difference observed at 6 months decreased over 24 months, but remained statistically significant. The black discoloration of the carious dentin after SDF treatment was probably the most notable undesirable side effect. In the study, there were no other adverse effects observed or complaints from either parents or the children concerning the SDF treatment.

Fung et al. $[17,18]$ reported that at 18 months followup, caries arrest rates were $50 \%, 55 \%, 64 \%$, and $74 \%$ for groups $1,2,3$, and 4 , respectively $(p<0.001)$ (Table 1 ). Lesions of the children receiving biannual SDF application had a higher chance of becoming arrested compared with those receiving annual SDF application (odds ratio [OR], 1.33; 95\% confidence interval [CI], 1.04-1.71; $p=0.025$ ). The interaction between concentration and lesion site was statistically significant $(p<0.001)$. Compared with $12 \%$ SDF, the use of 38\% SDF increased a chance of becoming arrested $(p<0.05)$, except lesions on occlusal surfaces. Based on the 18 months' results, SDF is more effective in arresting dentin caries in the primary teeth of preschool children at $38 \%$ concentration than $12 \%$ concentration and when applied biannually rather than annually.

While at the 30 months' examination, the mean (SD) numbers of tooth surfaces with arrested caries were 2.59 (2.94), 2.85 (2.91), 3.20 (3.71), and 3.49 (3.27) for groups $1,2,3$, and 4, respectively (ANOVA, $p=0.030$; post hoc Bonferroni test: group $1<$ group $4, p=0.032$ ) (Table 1 ). Moreover, the caries arrest rates were $55.2 \%, 58.6 \%$, $66.9 \%$, and $75.7 \%$ for groups $1,2,3$, and 4 , respectively $(p<0.001)$. Caries treated with $38 \%$ SDF had a higher chance of becoming arrested than those treated with $12 \%$ SDF (OR, 1.98; 95\% CI, 1.51-2.60, $p<0.001$ ). The interaction between the frequency of SDF application and visible plaque index (VPI) score was significant $(p=0.017)$. Among those children who received annual SDF application, children with a higher VPI score had a 
Table 1 Summary of the studies selected for this systematic review

\begin{tabular}{|c|c|c|c|c|c|c|}
\hline Study ID & $\begin{array}{l}\text { Subjects } \\
\text { age } \\
\text { (years) } \\
\text { Range, } \\
\text { mean } \\
\text { (SD) }\end{array}$ & Teeth & $\begin{array}{l}\text { Total no. of } \\
\text { patients/ } \\
\text { drop out }\end{array}$ & Grouping & $\begin{array}{l}\text { Trial } \\
\text { length/ } \\
\text { months }\end{array}$ & Outcome \\
\hline $\begin{array}{l}\text { Yee } \\
\text { et al. } \\
\text { [16] }\end{array}$ & $\begin{array}{l}3-9,5.2 \\
(1.2)\end{array}$ & $\begin{array}{l}\text { Primary } \\
\text { teeth }\end{array}$ & $\begin{array}{l}976 \\
\text { children } \\
\text { At } 6 \\
\text { months, } \\
908 \\
\text { At } 12 \\
\text { months, } \\
768 \\
\text { At } 24 \\
\text { months, } \\
634\end{array}$ & $\begin{array}{l}\text { Group 1: One application of } \\
38 \% \text { SDF for } 2 \text { min without a } \\
\text { reducing agent } \\
\text { Group 2: One application of } \\
38 \% \text { SDF for } 2 \text { min with tea } \\
\text { as a reducing agent } \\
\text { Group 3: One application of } \\
12 \% \text { SDF for } 2 \text { min without } \\
\text { a reducing agent } \\
\text { Group 4: No treatment for } \\
\text { carious teeth } \\
\text { This was the control group. }\end{array}$ & 24 & $\begin{array}{l}\text { Mean number of active cavitated } \\
\text { surfaces at baseline that changed at } 6,12, \\
\text { and } 24 \text { months' follow-up examination into } \\
\text { surfaces with arrested cavitated caries }\end{array}$ \\
\hline $\begin{array}{l}\text { Fung } \\
\text { et al. } \\
{[17,18]^{*}}\end{array}$ & $\begin{array}{l}3-4,3.8 \\
(0.6)\end{array}$ & $\begin{array}{l}\text { Primary } \\
\text { teeth }\end{array}$ & $\begin{array}{l}888 \\
\text { children } \\
\text { At } 6 \\
\text { months, } \\
888 \\
\text { At } 12 \\
\text { months, } \\
850 \\
\text { At } 18 \\
\text { months, } \\
831 \\
\text { at } 24 \\
\text { months, } \\
806 \\
\text { at } 30 \\
\text { months, } \\
799\end{array}$ & $\begin{array}{l}\text { Group 1: } 12 \% \text { SDF applied } \\
\text { every } 12 \text { months } \\
\text { Group 2: } 12 \% \text { SDF applied } \\
\text { every } 6 \text { months } \\
\text { Group 3: 38\% SDF applied } \\
\text { every } 12 \text { months } \\
\text { Group 4: 38\% SDF applied } \\
\text { every } 6 \text { months }\end{array}$ & $\begin{array}{l}18(2016) \\
30(2018)\end{array}$ & $\begin{array}{l}\text { Tooth surface-level caries arrest rates at } \\
6,12,18,24 \text {, and } 30 \text { months' examinations } n / N(\%) \text {. } \\
\text { Mean (SD) numbers of tooth surfaces with arrested } \\
\text { caries at } 30 \text { months follow-up. }\end{array}$ \\
\hline
\end{tabular}

*Fung et al.: Two publication reports with different follow-up [first 2016 (6, 12, and 18 months follow-up); second 2018 (24 and 30 months follow-up)]

lower chance to have their caries become arrested (OR, 0.59; 95\% CI, 0.49-0.72). The study did not report any major long-term or permanent adverse effects, apart from the black staining on the arrested caries lesions at 18 and 30 months follow-up.
The three publications had a low risk of bias regarding the sequence generation, performance bias (as dentists and personnel were blinded), blinding of outcome assessors, selective reporting bias, and other risks of bias [16-18]. The allocation concealment was at low risk of

Table 2 Caries arrestment-12\% SDF versus 38\% SDF

\begin{tabular}{|c|c|c|c|c|c|c|c|}
\hline \multirow{2}{*}{\multicolumn{2}{|c|}{$\frac{\%}{\text { Study ID }}$}} & \multicolumn{3}{|l|}{$12 \% \mathrm{SDF}$} & \multicolumn{3}{|l|}{$38 \%$ SDF } \\
\hline & & \multirow{2}{*}{$\begin{array}{l}\text { Yee et al. [16] } \\
\text { One at baseline } \\
\text { for } 2 \text { min }\end{array}$} & \multicolumn{2}{|c|}{ Fung et al. $[17,18]^{*}$} & \multirow{2}{*}{$\begin{array}{l}\text { Yee et al. [16] } \\
\text { One at baseline } \\
\text { for } 2 \text { min }\end{array}$} & \multicolumn{2}{|c|}{ Fung et al. $[17,18]^{*}$} \\
\hline Application fre & ency & & $\begin{array}{l}\text { At baseline and } \\
\text { every } 12 \text { months }\end{array}$ & $\begin{array}{l}\text { At baseline and } \\
\text { every } 6 \text { months }\end{array}$ & & $\begin{array}{l}\text { At baseline and } \\
\text { every } 12 \text { months }\end{array}$ & $\begin{array}{l}\text { At baseline and } \\
\text { every } 6 \text { months }\end{array}$ \\
\hline \multirow[t]{6}{*}{$\begin{array}{l}\text { Follow-up } \\
\text { examinations }\end{array}$} & $\begin{array}{l}6 \\
\text { months }\end{array}$ & $2.3(0.2)^{\dagger}$ & $337 / 1051(32.1)^{\ddagger}$ & $346 / 1072(32.3)^{\ddagger}$ & $4.2(0.3)^{\dagger}$ & $471 / 1073(43.9)^{\ddagger}$ & $449 / 1024(43.8)^{\ddagger}$ \\
\hline & $\begin{array}{l}12 \\
\text { months }\end{array}$ & $1.7(0.3)^{\dagger}$ & $409 / 1007(40.6)^{\ddagger}$ & $502 / 1046(48.0)^{\ddagger}$ & $3.4(0.3)^{\dagger}$ & $540 / 1041(51.9)^{\ddagger}$ & $618 / 987(62.6)^{\ddagger}$ \\
\hline & $\begin{array}{l}18 \\
\text { months }\end{array}$ & & $487 / 976(49.9)^{\ddagger}$ & $566 / 1028(55.1)^{\ddagger}$ & & $649 / 1019(63.7)^{\ddagger}$ & $701 / 953(73.6)^{\ddagger}$ \\
\hline & $\begin{array}{l}24 \\
\text { months }\end{array}$ & $1.5(0.3)^{\dagger}$ & $504 / 937(53.8)^{\ddagger}$ & $591 / 999(59.2)^{\ddagger}$ & $2.1(0.3)^{\dagger}$ & $620 / 971(63.9)^{\ddagger}$ & $698 / 912(76.5)^{\ddagger}$ \\
\hline & \multirow{2}{*}{$\begin{array}{l}30 \\
\text { months }\end{array}$} & & $512 / 927(55.2)^{\ddagger}$ & $578 / 987(58.6)^{\ddagger}$ & & $650 / 971(66.9)^{\ddagger}$ & $685 / 905(75.7)^{\ddagger}$ \\
\hline & & & $2.59(2.94)^{\dagger}$ & $2.85(2.91)^{\dagger}$ & & $3.20(3.71)^{\dagger}$ & $3.49(3.27)^{\dagger}$ \\
\hline
\end{tabular}

*Fung et al.: Two publication reports with different follow-up [first 2016 (6, 12, and 18 months follow-up); second 2018 (24 and 30 months follow-up)] Outcome measurement units: ${ }^{\dagger}$ mean (SD) numbers, ${ }^{\ddagger}$ caries arrest rate $n / N(\%)$ 
bias in one publication [18] and "unclear" in the other two publications [16, 17]. Regarding blinding of patients, two publications were at low risk of bias $[17,18]$ and one was at "unclear" risk [16]. Risk of incomplete outcome data (attrition bias) showed a low risk of bias in two publications $[17,18]$ and a high risk of bias in one publication [16]. Risk of bias assessment is presented in Fig. 2 and Additional file 1: Tables S1-3.

\section{Discussion}

Silver diamine fluoride (SDF) at a concentration of $38 \%$ $(44,800 \mathrm{ppm}$ fluoride) is the highest among fluoride agents used in dental practice [8]. Gao et al. [19] in a systematic review reported that it is the most commonly used concentration and is effective in arresting caries among children.

This high fluoride concentration has been an area for concern because of the possible risk of dental fluorosis. SDF stains carious dentin black permanently due to the formation of silver phosphate [4], particularly with the used of higher concentrations and/or more frequent repeated applications [13]. This dark staining may limit its clinical use due to cosmetic purposes especially with esthetically demanding patients, particularly when used over the visible upper anterior teeth surfaces, which happen to be the common sites for ECC [13]. Hence, a lower concentration of $12 \%$ (14,150 ppm fluoride) has been introduced for the purpose of minimizing the incidence of such complication [20].
The present systematic review was performed in six databases, Grey Literature Report, manual search, and the ClinicalTrials.gov registry, yet the number of publications meeting inclusion criteria was only three [16-18]. Regarding the three included publications, two of them were follow-up publication reports for one clinical trial. Hence, a meta-analysis could not be performed on these studies.

The protocol of SDF application in the first publication was one application at baseline with 6,12 , and 24 months follow-up. The outcome measurement unit was mean (SD) numbers at all follow-up examinations [16]. While in the other two publications, it was annual and biannual SDF applications with 6, 12, 18, 24, and 30 months follow-up. The outcome measurement units were caries arrest rates at all follow-up examinations as $n / N(\%)$ and mean (SD) numbers at 30 months followup only $[17,18]$. This non-similarity made the comparison difficult. However, the three publications showed that caries of primary teeth in children treated with $38 \%$ SDF had higher chances of becoming arrested than those treated with $12 \%$ SDF.

Furthermore, Yee et al. [16] reported that the outcomes of 24 months' SDF study of a single spot application of 38\% SDF were effective in arresting caries lesions, but this effectiveness decreased over time, and that $12 \%$ SDF was not effective, while Fung et al. [17] found that SDF is more effective in arresting dentin caries in the primary teeth of preschool children at $38 \%$ concentration than the $12 \%$ concentration when applied biannually rather than annually, assessed at 18 months

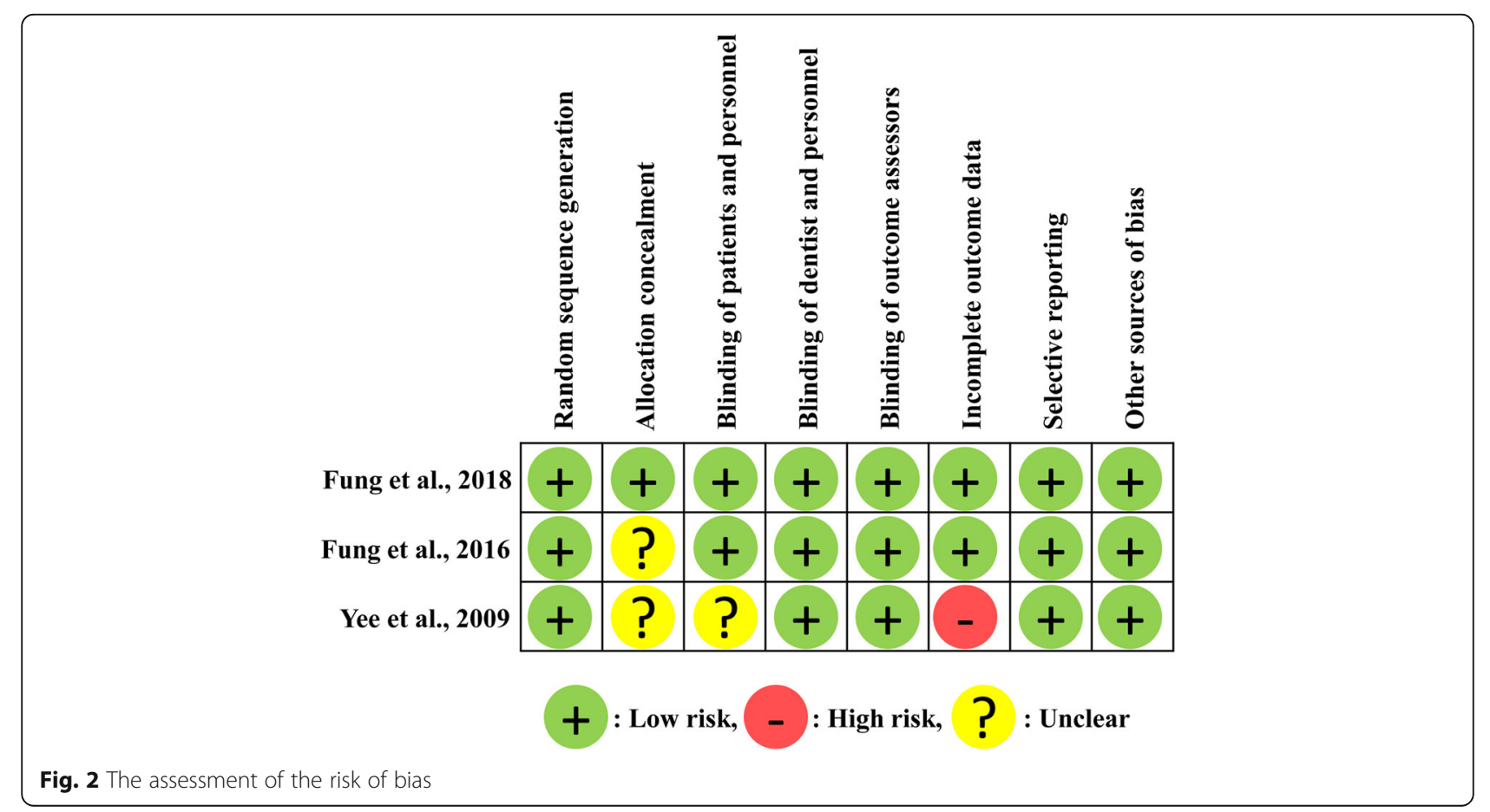


follow-up. These findings were consistent with the 30 months follow-up reported in 2018 [18].

In the current systematic review, the children were up to 9 years of age; however, the three publications included only primary teeth. This could be attributed to the fact that SDF is not commonly used in permanent teeth, probably due to the staining potential and primary teeth exfoliation [5].

Moreover, Fung and his colleagues published another article in the year 2018 under the authorship of Duangthip et al. [21] assessing the adverse effects of SDF application which was mainly the black staining, using the same participants and excluding any variations. They reported that there were statistically significant differences in the numbers of blackened carious lesions among four SDF groups (annual and semiannual applications, for the 12\% and $38 \%$ SDF concentrations) at 18 and 30 months followup $\left(\chi^{2}\right.$ test, $\left.p<0.001\right)$. When compared with those treated with $12 \%$ SDF, lesions in the children receiving 38\% SDF had a higher chance of becoming black (OR, 3.29; 95\% CI, 2.84 to $3.81 ; p<0.001)$. Lesions treated semiannually had a higher chance of becoming black than those treated annually (OR, 1.69; 95\% CI, 1.46 to $1.95 ; p<0.001)$.

Further research is necessary to find a protocol that is effective in arresting dental caries yet avoids or minimizes the staining problem of SDF.

\section{Conclusions}

Based on this systematic review of the included primary studies, 38\% SDF solution is more effective in arresting dentin caries of primary teeth compared to $12 \%$ SDF. Further primary clinical trials are needed to develop evidence-based protocols concerning SDF lowest effective concentration with reasonable frequency of application for arresting caries.

\section{Additional file}

Additional file 1: Table S1. Risk of bias tool for Yee et al. [16]. Table S2. Risk of bias tool for Fung et al. [17]. Table S3. Risk of bias tool for Fung et al. [18] (DOCX 23 kb)

\footnotetext{
Abbreviations

ANOVA: Analysis of variance; Cl: Confidence interval; ECC: Early childhood caries; ID: Identity; LILACS: Literatura Latino-Americana e do Caribe em Ciências da Saúde, Latin American and Caribbean Health Sciences Literature; MeSH: Medical Subject Headings; NICE: National Institute for Health and Care Excellence; OR: Odds ratio; $p$ value: Probability value or significance; PICO: Participant, Intervention, Comparator, Outcome; PRISMA: Preferred Reporting Items for Systematic Reviews and Meta-Analyses; RCTs: Randomized clinical trials; S: Supplementary; SD: Standard deviation; SDF: Silver diamine fluoride; TRIP: Turning Research Into Practice; $x^{2}$ test: Chi-squared test
}

\section{Authors' contributions}

ZO contributed to the conception and design of the study, literature search, definition of intellectual content, acquisition of data, data analysis, manuscript preparation, manuscript editing, and manuscript review; is the guarantor; and approved the final version of the manuscript to be published. $\mathrm{HH}$ contributed to the conception and design of the study, literature search, definition of intellectual content, acquisition of data, data analysis, and manuscript review and approved the final version of the manuscript to be published. DM contributed to the conception and design of the study and manuscript review and approved the final version of the manuscript to be published. HE contributed to the conception of the study, manuscript preparation, and manuscript editing and approved the final version of the manuscript to be published. HS contributed to the conception of the study, manuscript editing, and manuscript review and approved the final version of the manuscript to be published.

Funding

None.

Availability of data and materials

All data generated or analyzed during this study are included in this published article and its additional file.

Ethics approval and consent to participate

Not applicable.

Consent for publication

Not applicable.

Competing interests

The authors declare that they have no competing interests.

Author details

${ }^{1}$ Conservative Dentistry Department, Faculty of Dentistry, Cairo University, 11 EL-Saraya St. Manial, Cairo 11553, Egypt. Pediatric Dentistry Department, Faculty of Dentistry, Cairo University, 11 EL-Saraya St. Manial, Cairo 11553, Egypt. ${ }^{3}$ Ruprecht-Karls-Universität Heidelberg, Postfach 1057 60, 69047 Heidelberg, Germany. ${ }^{4}$ Giza, Egypt.

Received: 31 May 2019 Accepted: 23 July 2019

Published online: 02 September 2019

\section{References}

1. Marcenes W, Kassebaum NJ, Bernabé E, Flaxman A, Naghavi M, Lopez A et al (2013) Global burden of oral conditions in 1990-2010: a systematic analysis. J Dent Res 92:592-597

2. Chu CH, Lo ECM, Lin HC (2002) Effectiveness of silver diamine fluoride and sodium fluoride varnish in arresting dentin caries in Chinese pre-school children. J Dent Res 81:767-770

3. Llodra JC, Rodriguez A, Ferrer B, Menardia V, Ramos T, Morato M (2005) Efficacy of silver diamine fluoride for caries reduction in primary teeth and first permanent molars of schoolchildren: 36-month clinical trial. J Dent Res 84:721-724

4. Shounia TY, Atwan S, Alabduljabbar R (2017) Using silver diamine fluoride to arrest dental caries: a new approach in the US. J Dent Oral Biol 2:1105

5. Chibinski AC, Wambier LM, Feltrin J, Loguercio AD, Wambier DS, Reis A (2017) Silver diamine fluoride has efficacy in controlling caries progression in primary teeth: a systematic review and meta-analysis. Caries Res 51:527-541

6. Rosenblatt A, Stamford TCM, Niederman R (2009) Silver diamine fluoride: a caries "silver-fluoride bullet". J Dent Res 88:116-125

7. Gao SS, Zhang S, Mei ML, Lo ECM, Chu CH (2016) Caries remineralisation and arresting effect in children by professionally applied fluoride treatmenta systematic review. BMC Oral Health 16:12

8. Zhao IS, Gao SS, Hiraishi N, Burrow MF, Duangthip D, Mei ML et al (2018) Mechanisms of silver diamine fluoride on arresting caries: a literature review. Int Dent J 68:67-76

9. Horst JA, Ellenikiotis H, Milgrom PL (2016) UCSF Protocol for caries arrest using silver diamine fluoride: rationale, indications and consent. J Calif Dent Assoc 44:16-28 
10. Braga MM, Mendes FM, De Benedetto MS, Imparato JCP (2009) Effect of silver diammine fluoride on incipient caries lesions in erupting permanent first molars: a pilot study. J Dent Child 76:28-33

11. Liu BY, Lo ECM, Chu CH, Lin HC (2012) Randomized trial on fluorides and sealants for fissure caries prevention. J Dent Res 91:753-758

12. Lo ECM, Chu CH, Lin HC (2001) A community-based caries control program for pre-school children using topical fluorides: 18-month results. J Dent Res 80:2071-2074

13. Fung MHT, Wong MCM, Lo ECM, Chu CH (2013) Arresting early childhood caries with silver diamine fluoride-a literature review. J Oral Hyg Health 1:117

14. Moher D, Liberati A, Tetzlaff J, Altman DG The PRISMA group (2009) Preferred reporting items for systematic reviews and meta-analyses: the PRISMA statement. PLoS Med 6:1-6. https://doi.org/10.1371/journal.pmed.1000097

15. Higgins JPT, Altman DG (2008) Assessing risk of bias in included studies. In: Higgins JPT, Green S (eds) Cochrane handbook for systematic reviews of interventions. Wiley, pp 187-241

16. Yee R, Holmgren C, Mulder J, Lama D, Walker D, van Palenstein Helderman W (2009) Efficacy of silver diamine fluoride for arresting caries treatment. J Dent Res 88:644-647

17. Fung MHT, Duangthip D, Wong MCM, Lo ECM, Chu CH (2016) Arresting dentine caries with different concentration and periodicity of silver diamine fluoride. JDR Clin Trans Res 1:143-152

18. Fung MHT, Duangthip D, Wong MCM, Lo ECM, Chu CH (2018) Randomized clinical trial of $12 \%$ and $38 \%$ silver diamine fluoride treatment. J Dent Res 97:171-178

19. Gao SS, Zhao IS, Hiraishi N, Duangthip D, Mei ML, Lo ECM et al (2016) Clinical trials of silver diamine fluoride in arresting caries among children: a systematic review. JDR Clin Trans Res 1:201-210

20. Mei ML, Chu CH, Lo ECM, Samaranayake LP (2013) Fluoride and silver concentrations of silver diammine fluoride solutions for dental use. Int $J$ Paediatr Dent 23:279-285

21. Duangthip D, Fung MHT, Wong MCM, Chu CH, Lo ECM (2018) Adverse effects of silver diamine fluoride treatment among preschool children. J Dent Res 97:395-401

\section{Publisher's Note}

Springer Nature remains neutral with regard to jurisdictional claims in published maps and institutional affiliations.

\section{Submit your manuscript to a SpringerOpen ${ }^{\circ}$ journal and benefit from:}

- Convenient online submission

- Rigorous peer review

- Open access: articles freely available online

- High visibility within the field

- Retaining the copyright to your article

Submit your next manuscript at $\boldsymbol{\nabla}$ springeropen.com 